\title{
Analysis of Lattice Design Using PC-SAS
}

\section{George C.J. Fernandez ${ }^{1}$ \\ Department of Plant Science, University of Nevada-Reno, Reno, NV 89557-0107}

Additional index words. Statistical Analysis System, general linear model, sequential sums of squares, type-III sums of squares

The Statistical Analysis System (SAS) package (SAS Institute, 1987) is a commonly used statistical software in agricultural research. The use of SAS in statistical analysis is rapidly increasing with the availability of command-driven SAS in personal computers (PC-SAS). In a recent study, PCSAS was identified as one of the more versatile and easy-to-use software programs available in the market (Milliken and Remmenga, 1989). In addition, PC-SAS is powerful in data management and flexible in formatting output. The relative ease with which the General Linear Model (GLM) procedure can be used in conjunction with data management makes PC-SAS a powerful tool for statistical analysis.

The use of SAS for analyzing experiments that incorporate a lattice design was discussed recently in a colloquium for horticulturists (Stroup and Paparozzi, 1989). PROC MATRIX and IML or PROC LATTICE, which is available in the Supplemental User's Library, were considered for analyzing experiments in lattice design using SAS with a main-frame computer (Stroup and Paparozzi, 1989). However, PROC LATTICE is not available in the PC-SAS base package and PROC MATRIX programming is complicated for the average user. Therefore, this paper presents a PC-SAS program for the analyses of data obtained from experiments using lattice designs.

Published data (Gomez and Gomez, 1984) from $9 \times 9$ triple lattice design was used to check the PC-SAS program for lattice design analyses. The same notations given by Gomez and Gomez (1984) in the analysis of lattice data were used in the SAS program for analyzing lattice data.

The SAS program for analyzing lattice design consists of two parts. In the first, PROC GLM was used to calculate unadjusted block SS (TYPE I SS-Sequential SS), adjusted block SS (TYPE III SS), unadjusted treatment SS, and intra-block error. To calculate the unadjusted block SS from TYPE I SS, the order in which variables were entered into the. model statement is important. The block (replicate) was entered before the treatment in the model statement (Fig. 1).

Received for publication 3 July, 1989. The cost of publishing this paper was defrayed in part by the payment of page charges. Under postal regulations, this paper therefore must be hereby marked advertisement solely to indicate this fact.

${ }^{1}$ Assistant Professor in Plant Breeding and Biometrics.
These estimates were used in the second part of the program to calculate the adjusted treatment SS, adjusted means, and the average effective error, respectively.

[Note: When PROC GLM is used to analyze large data sets, as in this example, an error might occur due to insufficient memory allocation. This problem can be overcome by directly submitting the SAS program without loading the display manager system (DMS). For example, if the SAS program file (lattice.prg) is on a floppy disk, then SAS can be called without the DMS by entering the following statement, $\mathrm{C}>S A S$ A:lattice.prg. The SAS log and the output will be automatically directed to the SAS directory.]

The second part of the lattice program (Fig. 1) consists of five sections. In the first seetion, treatment totals $(\mathrm{T})$ were calculated using the PROC MEANS procedure. The block totals (B) and the sum of treatment totals for
Fig. 1. PC-SAS program for analyzing lattice design. all treatments appearing in a particular block (M) were calculated in the second section using the MERGE option and the PROC MEANS procedure. The adjusted block values $\left(\mathrm{C}_{\mathrm{b}}\right)$, their sum $\left(\Sigma \mathrm{C}_{\mathrm{b}}\right)$, and the treatment totals $(\mathrm{T})$ were calculated in the next section. The adjusted value (A), adjusted treatment means square (ADTRTMS), F value, and the average effective error (AVEERR) were calculated using the estimates obtained from GLM. Finally, the adjustment factor $(\mu)$, adjusted treatment total (AT), and the adjusted treatment mean (TM) were calculated.

This simple SAS program provides a way of analyzing lattice design using PROC GLM, PROC MEANS, and data manipulations. This program required $\approx 8 \mathrm{~min}$ to analyze these data in an IBM-compatible AT computer. Although this program is written for a $9 \times$ 9 triple lattice design, it could be easily modified to analyze other lattice designs by changing the equations to calculate adjustment factor $(\mu)$ and the adjustment value $(\mathrm{A})$.

\section{Literature Cited}

Gomez, K.A. and A.A. Gomez. 1984. Statistical procedures for agricultural research. Wiley, New York.

Milliken, G.A. and M.D. Remmenga. 1989. Statistical analysis and the personal computer. HortScience 24:45-52.

SAS Institute. 1987. SAS/STAT guide for personal computers. version 6 (ed.). SAS Institute, Inc., Cary, N.C.

Stroup, W.W. and E.T. Paparozzi. 1989. Summary, comments, and question and answer session. HortScience 24:58-61.

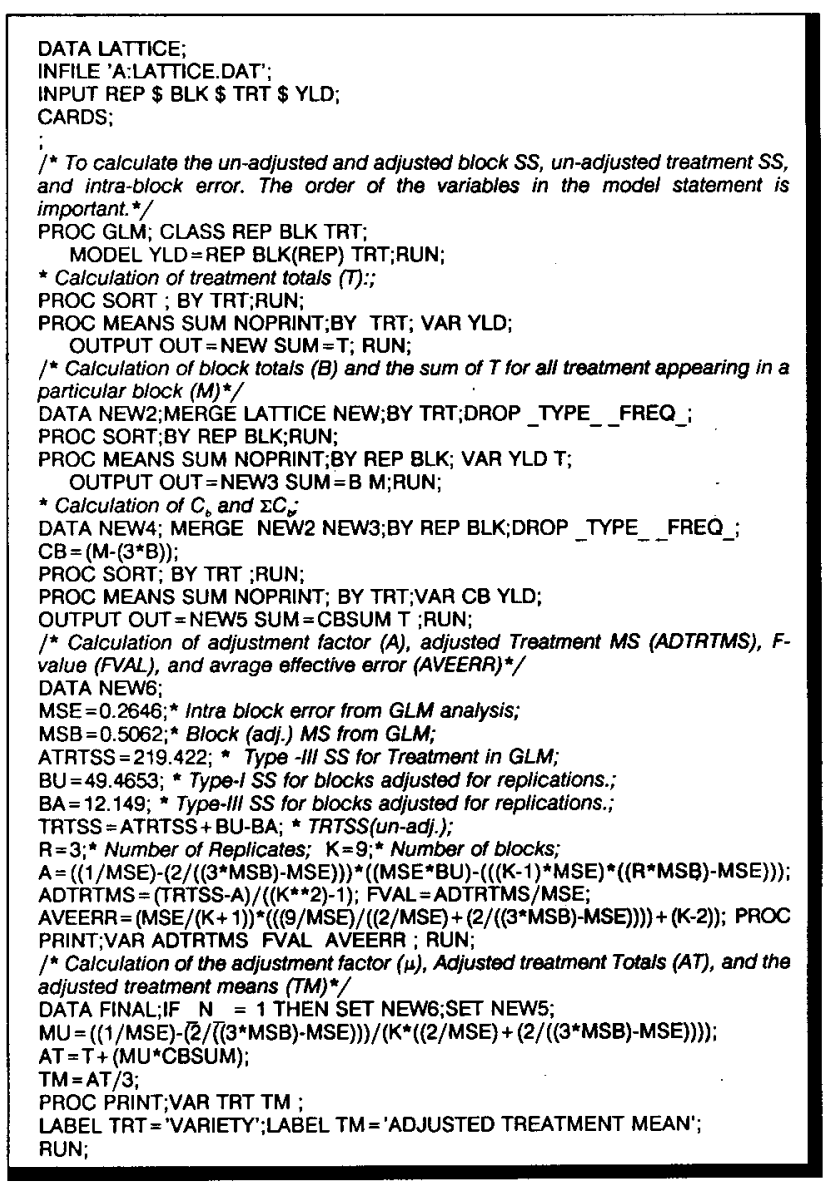

